\title{
Minimum inhibitory concentration of vancomycin to methicillin resistant Staphylococcus aureus isolated from different clinical samples at a tertiary care hospital in Nepal
}

\author{
Arjun Ojha Kshetry ${ }^{1}$, Narayan Dutt Pant ${ }^{2 *}$, Raju Bhandari ${ }^{1}$, Sabita Khatri ${ }^{1}$, Krishma Laxmi Shrestha $^{1}$,
} Shambhu Kumar Upadhaya ${ }^{1}$, Asia Poudel ${ }^{1}$, Binod Lekhak ${ }^{1}$ and Bijendra R. Raghubanshi ${ }^{3}$

\begin{abstract}
Background: Methicillin resistant Staphylococcus aureus (MRSA) has evolved as a serious threat to public health. It has capability to cause infections not only in health care settings but also in community. Due to the multidrug resistance shown by MRSA, there are limited treatment options for the infections caused by this superbug. Vancomycin is used as the drug of choice for the treatment of infections caused by MRSA. Different studies from all around the world have documented the emergence of strains of $S$. aureus those are intermediate sensitive or resistant to vancomycin. And recently, there have been reports of reduced susceptibility of MRSA to vancomycin, from Nepal also. So the main purpose of this study was to determine the minimum inhibitory concentration (MIC) of vancomycin to methicillin resistant $S$. aureus isolated from different clinical specimens.
\end{abstract}

Methods: Total 125 strains of S. aureus isolated from different clinical samples at KIST Medical College and Teaching Hospital, Lalitpur, Nepal from Nov 2012 to June 2013, were subjected to MRSA detection by cefoxitin disc diffusion method. The minimum inhibitory concentrations of vancomycin to confirmed MRSA strains were determined by agar dilution method. Yellow colored colonies in mannitol salt agar, which were gram positive cocci, catalase positive and coagulase positive were confirmed to be $S$. aureus.

Results: Among, total 125 S. aureus strains isolated; 47(37.6\%) were MRSA. Minimum inhibitory concentrations of vancomycin to the strains of MRSA ranged from $0.125 \mu \mathrm{g} / \mathrm{ml}$ to $1 \mu \mathrm{g} / \mathrm{ml}$.

Conclusion: From our findings we concluded that the rate of isolation of MRSA among all the strains of $S$. aureus isolated from clinical samples was very high. However, none of the MRSA strains were found to be vancomycin intermediate-sensitive or vancomycin-resistant.

Keywords: S. aureus, MRSA, VRSA, VISA, Nepal

\footnotetext{
* Correspondence: ndpant1987@gmail.com

${ }^{2}$ Department of Microbiology, Grande International Hospital, Dhapasi,

Kathmandu, Nepal

Full list of author information is available at the end of the article
}

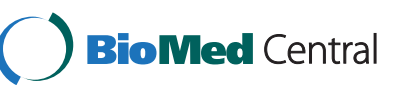

(C) 2016 The Author(s). Open Access This article is distributed under the terms of the Creative Commons Attribution 4.0 International License (http://creativecommons.org/licenses/by/4.0/), which permits unrestricted use, distribution, and reproduction in any medium, provided you give appropriate credit to the original author(s) and the source, provide a link to the Creative Commons license, and indicate if changes were made. The Creative Commons Public Domain Dedication waiver (http://creativecommons.org/publicdomain/zero/1.0/) applies to the data made available in this article, unless otherwise stated. 


\section{Background}

Staphylococcus aureus is present as the normal flora of humans; on skin and anterior nares and up to two-third of the population is colonized by it [1]. It is a pathogenic bacterium; which may be responsible for causing a broad spectrum of diseases in hospital as well as the community and can develop drug resistance to commonly used antibiotics in short period of time [2]. Most importantly, $S$. aureus causes skin and soft tissue infections but it can also cause fatal diseases like endovascular infections and sepsis [2-4]. Colonization of the anterior nares in humans is one of the most important risk factors for infection by $S$. aureus [5]. Despite the development of improved surgical techniques and antibiotic prophylaxis, the infections caused by $S$. aureus present as a serious public health problems [6]. Virtually no strains of $S$. aureus are known to be intrinsically resistant to any antibiotics developed till date [7].

Since 1960s, methicillin-resistant S. aureus (MRSA) has established itself as one of the commonest causes of nosocomial infections and its dissemination to the community has created a more dreadful situation [8, 9]. For the treatment of MRSA; vancomycin is used as drug of choice [10]. However, there are increasing numbers of reports on emergence of vancomycin intermediatesensitive $S$. aureus (VISA) and vancomycin-resistant $S$. aureus (VRSA) [11]. In addition, many researchers have reported the higher rates of likelihood of treatment failure leading to higher rates of mortality, due to the infection caused by MRSA having MIC of vancomycin at the upper end of susceptible range [12]. The higher MIC of vancomycin to MRSA even in the susceptible range correlates with the drug resistance to many different classes of the antibiotics [11]. Till date no VRSA has been reported from Nepal but the increasing trends of decreased susceptibility of the strains of MRSA to vancomycin reported from Nepal, indicate the need of more researches in the field [13]. In Nepal, only limited data are available on the susceptibility of MRSA to reserve drug, vancomycin. So, in this study we determined the minimum inhibitory concentration of vancomycin to methicillin resistant Staphylococcus aureus isolated from different clinical specimens.

\section{Methods}

The study was conducted at KIST Medical College and Teaching Hospital, Lalitpur, Nepal from Nov 2012 to June 2013, using the total of 125 strains of Staphylococcus aureus isolated from different clinical samples. Yellow colored colonies on mannitol salt agar, which were gram positive cocci, catalase positive and coagulase positive were confirmed to be $S$. aureus. Antimicrobial susceptibility testing of $S$. aureus to penicillin and vancomycin was performed by modified Kirby-Bauer disc diffusion technique, following clinical and laboratory standards institute (CLSI) guidelines [14].

\section{Detection of methicillin resistant $S$. aureus}

Detection of MRSA was performed by using cefoxitin disc $(30 \mu \mathrm{g})$. For this lawn culture was performed on Mueller-Hinton agar plate, using the broth culture of $S$. aureus with turbidity adjusted to $0.5 \mathrm{McF}$ arland standard. Then a cefoxitin disc $(30 \mu \mathrm{g})$ was kept on the lawn culture after it had been left to dry for about $5 \mathrm{~min}$. Finally, the agar plate was incubated aerobically at $35{ }^{\circ} \mathrm{C}$ for $18 \mathrm{~h}$. The strains showing diameter of zone of inhibition of $\leq 21 \mathrm{~mm}$ were considered as methicillin resistant $S$. aureus (MRSA) while those with diameter of zone of inhibition of $\geq 22 \mathrm{~mm}$ were identified as methicillin susceptible S. aureus (MSSA) [14].

\section{Screening of $\beta$-lactamase producers among $S$. aureus}

Penicillin disc zone-edge test was used to identify the $\beta$ lactamase producing strains of $S$. aureus. For this penicillin G (10 units) disc was used. The strains showing sharp zone edge were screened to be $\beta$-lactamase producers while those indicating fuzzy zone edge were considered to be $\beta$-Lactamase non-producers [14].

\section{Determination of minimum inhibitory concentration of vancomycin to MRSA}

The minimum inhibitory concentrations of vancomycin to the strains of MRSA were determined by agar dilution method as suggested by Andrews [15] following CLSI guidelines [14]. The different dilutions of vancomycin used were $0.0625 \mu \mathrm{g} / \mathrm{ml}$ to $64 \mu \mathrm{g} / \mathrm{ml}$.

\section{Quality control}

For quality control S. aureus (ATCC 25923) was used.

\section{Data analysis}

The data obtained were analysed by using statistical package for social sciences (SPSS) version 16. Chi-square test was used and p-value $<0.05$ was taken as significant.

\section{Results}

Among a total of $125 \mathrm{~S}$. aureus isolates, 47(37.6\%) were methicillin resistant (MRSA).

Distribution of S. aureus on the basis of different clinical specimens

Most of the strains of $S$. aureus were isolated from pus (66.4\%) followed by blood (13.6\%) and urine (8.8\%) (Table 1).

Distribution of MRSA on the basis of different parameters All the patients were categorized into two categories $(<18$ years of age as pediatric and the people $>19$ years 
Table 1 Distribution of S. aureus on the basis of different clinical specimens

\begin{tabular}{llll}
\hline Clinical Specimens & \multicolumn{2}{l}{ S. aureus } & Total (\%) \\
\cline { 2 - 3 } & MRSA & MSSA & \\
\hline Pus & 27 & 56 & $83(66.4)$ \\
Blood & 10 & 7 & $17(13.6)$ \\
CAPD fluid & 1 & 0 & $1(0.8)$ \\
Sputum & 4 & 6 & $10(8)$ \\
Urine & 3 & 8 & $11(8.8)$ \\
Sub-Clavian Tip & 2 & 0 & $2(1.6)$ \\
Breast Milk & 0 & 1 & $1(0.8)$ \\
Total & 47 & 78 & 125 \\
\hline
\end{tabular}

of age as adult). In our study, 29 strains of MRSA were isolated from adults while 18 isolates of MRSA were isolated from pediatric patients and the difference was statistically insignificant $(p>0.05)$. Similarly, 30 MRSA strains were isolated from male and 17 MRSA strains were isolated from female. The distribution of MRSA among the patients on the basis of sex was found to be statistically significant $(p<0.05)$. Further, 28 isolates of MRSA were isolated from in-patients department while 19 MRSA strains were isolated from out-patient department and the difference was statistically insignificant $(p>0.05)$ (Table 2).

Rate of $\beta$-lactamase production among penicillin resistant S. aureus

All the $125 \mathrm{~S}$. aureus isolates were resistant to penicillin by disc diffusion technique. However, only 69(55.2\%) of the isolates were found to be resistant to penicillin due to $\beta$-lactamase production.

Distribution of $\beta$-lactamase producer penicillin resistant $S$. aureus on the basis of different parameters

The distribution of $\beta$-lactamase producer penicillin resistant $S$. aureus on the basis of different parameters like age, sex and departments was found to be statistically insignificant $(P>0.05)$ (Table 3$)$.

Table 2 Distribution of MRSA on the basis of different parameters

\begin{tabular}{lllll}
\hline Parameters & & MSSA & MRSA & P-value \\
\hline Age & Pediatric & 19 & 18 & 0.098 \\
\multirow{4}{*}{ Gender } & Adult & 59 & 29 & \\
& Male & 30 & 30 & 0.006 \\
\multirow{2}{*}{ Department } & Female & 48 & 17 & \\
& OPD & 44 & 19 & 0.083 \\
& IPD & 34 & 28 & \\
\hline
\end{tabular}

Table 3 Distribution of $\beta$-lactamase producing and nonproducing S. aureus

\begin{tabular}{lllll}
\hline Parameters & & \multicolumn{2}{l}{$\beta$-lactamase production } & P-value \\
\cline { 3 - 4 } & & + & - & \\
\hline Age & Pediatric & 19 & 18 & 0.575 \\
\multirow{2}{*}{ Gender } & Adult & 50 & 38 & \\
& Male & 28 & 32 & 0.065 \\
\multirow{2}{*}{ Department } & Female & 41 & 24 & \\
& OPD & 37 & 26 & 0.424 \\
& IPD & 32 & 30 & \\
\hline
\end{tabular}

Note: $+=$ Positive, $-=$ Negative

\section{Minimum inhibitory concentrations (MIC) of vancomycin to MRSA isolates}

Most of the strains of MRSA showed resistance toward vancomycin on performing antimicrobial susceptibility testing by disc diffusion method using vancomycin disc. However, the determination of minimum inhibitory concentrations of vancomycin to MRSA isolates showed that all the strains of MRSA were susceptible to vancomycin with MIC ranging from $0.125 \mu \mathrm{g} / \mathrm{ml}$ to $1 \mu \mathrm{g} / \mathrm{ml}$. The numbers of the MRSA isolates having different MIC of vancomycin and showing different sizes of zone of inhibition for vancomycin disc are given in Table 4.

\section{Discussion}

S. aureus is a flexible pathogen, which may be responsible for causing community acquired as well as nosocomial infections [1]. Despite the years of efforts to develop the new antibiotics for the eradication of MRSA, it has established itself as the commonest cause of skin and soft tissue infections [16, 17]. The prevalence of MRSA in our study was $47 / 125(37.6 \%)$, which was consistent with the results reported by Sanjana et al. (39.6\%) [18] and Juayang et al. (40.6\%) [19]. However, lower prevalence of MRSA in comparison to our study were reported by Subedi et al. (15.4\%) [20], Baral et al. (26\%) [21], Pandey et al. (26.12\%) [22] and Kumari et al. (26.14\%) [23]. While higher prevalence of MRSA were reported by Arora et al. (46\%) [24], Dibah et al. (46.3\%) [25], Khanal et al. (68\%) [26] and Tiwari et al., (69.1\%) [27]. The difference in the prevalence of MRSA among

Table 4 Minimum inhibitory concentrations of vancomycin to MRSA isolates versus zones of inhibition of MRSA for vancomycin

\begin{tabular}{|c|c|c|c|c|c|c|c|c|c|c|c|}
\hline \multirow{2}{*}{$\begin{array}{l}\text { MIC of } \\
\text { vancomycin } \\
(\mu \mathrm{g} / \mathrm{ml})\end{array}$} & \multicolumn{11}{|c|}{ Zones of inhibition for vancomycin (mm) } \\
\hline & 6 & 7 & 8 & 9 & 10 & 11 & 12 & 13 & 14 & 15 & 16 \\
\hline 0.125 & & & & & & 1 & & 1 & 1 & & 1 \\
\hline 0.25 & & & & 1 & 1 & 1 & 1 & 1 & 1 & & \\
\hline 0.5 & 2 & & 3 & 1 & 5 & 1 & 4 & 4 & 3 & 1 & 4 \\
\hline 1 & 1 & 1 & & 1 & 1 & 1 & 2 & & 2 & & \\
\hline
\end{tabular}


different studies may be due to difference in the location and time period of the study. The prevalence of MRSA may differ from one hospital to another hospital, depending upon the types of the patients it receives, hygienic condition of the hospital and the health care workers. If the hospital is a referral center then the prevalence of the MRSA among the patients may be very high, as the chance of getting antimicrobial therapy before reaching the referral center is very high and due to selective pressure the bacteria may acquire drug resistance. Healthcare workers may be not only the important source of transmission of MRSA to patients or among patients but also to the community [28]. Strict implementation of hand hygiene and decolonization of the MRSA carriers will be helpful to control the transmission of MRSA [11]. In addition, maintaining good (environmental as well as personal) hygiene in the hospital, among healthcare workers and patients will be more beneficial [11]. Due to the availability of limited treatment options for infections caused by MRSA, the treatment of such infections is often difficult leading to prolonged hospital stay and longer course along with higher cost of treatment sometimes leading to treatment failure resulting into fatal outcome [28]. Further, the higher rate of isolation of MRSA from clinical specimens of patients suggests the more attention to be given for infection control and surveillance, which may increase the overall infection control cost in the hospital [29].

In our study no strains of MRSA were found to be vancomycin resistant or vancomycin intermediate sensitive and the minimum inhibitory concentrations of vancomycin to the strains of MRSA ranged from $0.125 \mu \mathrm{g} / \mathrm{ml}$ to $1 \mu \mathrm{g} / \mathrm{ml}$. As in our study, in a research from Nepal; Amatya et al. also did not note any strains of MRSA to be VISA or VRSA but higher MIC (i.e., $0.5 \mu \mathrm{g} / \mathrm{ml}$ to $2 \mu \mathrm{g} / \mathrm{ml}$ ) of vancomycin to MRSA (in comparison to our study) was reported [11]. In contrast, in another study from Nepal; Pahadi et al. reported the four isolates of the MRSA to be VISA, with MIC of vancomycin to all the MRSA, ranging from $0.5 \mu \mathrm{g} / \mathrm{ml}$ to $4 \mu \mathrm{g} /$ $\mathrm{ml}$ [13]. The discrepancy seen in results of different studies conducted in Nepal, may be because of the involvement of the patients with previous history of exposure to vancomycin in some studies. No VRSA has yet been reported from Nepal [13]. Decreased susceptibility of $S$. aureus to vancomycin was reported first from Japan in 1997 [30]. And the first strain of VRSA was isolated in 2002 from Michigan, USA [31]. Since then the VISA and VRSA have been reported frequently by many researchers [32-36].

The mechanism behind the resistance of Staphylococcus aureus to vancomycin may be the thickening of cell wall [37]. In addition; prior exposure to vancomycin increases the chances of the isolation of the strains of
Staphylococcus aureus with reduced susceptibility [11] and the reason for emergence of VRSA/VISA may be the selective pressure due to the haphazard use of the antibiotic (vancomycin) [11]. The morbidity and mortality due to infection caused by VRSA are very high because of limited treatment options available [33]. At present when the infections due to MRSA have become a serious public health concern; the development and rapid spread of resistance of $S$. aureus to the reserve drug (vancomycin) is very fearsome and immediate actions should to be taken by the responsible authorities to halt it [11].

Due to haphazard use of antibiotics, there is increasing trend of development of drug resistance among the bacteria and the condition is more critical in poorer countries [38, 39]. To prevent the situation of the drug resistance from worsening; the use of antibiotic for the treatment of the patients should be based on culture and sensitivity report [40].

\section{Limitations of the study}

Inability to use the molecular methods in our study is the main limitation of our research. Further, we could not differentiate between community acquired MRSA and hospital acquired MRSA. In addition, we were unable to include more samples in our study. National level study involving large numbers of samples would have generated more significant results and the actual situation of the MIC of vancomycin to MRSA, in Nepal.

\section{Conclusion}

In our study the rate of isolation of MRSA among all the strains of $S$. aureus was very high. But none of the MRSA strains were found to be vancomycin intermediate-sensitive or vancomycin-resistant. The MIC of vancomycin for MRSA in our study was found to be lower in comparison to similar other studies conducted in Nepal.

\section{Abbreviations \\ ATCC, American Type Culture Collection; CAPD, continuous ambulatory peritoneal dialysis; CLSI, Clinical and laboratory Standards Institute; IPD, In patient Department; MIC, minimum inhibitory concentration; MRSA, methicillin resistant S. aureus; MSSA, methicillin susceptible S. aureus; OPD, Out Patient Department; SPSS, Statistical Package for the Social Sciences; USA, United States of America; VISA, vancomycin intermediate sensitive S. aureus; VRSA, vancomycin resistant S. aureus}

\section{Acknowledgements}

The authors would like to thank KIST Medical College and Teaching Hospital, Lalitpur, Nepal for providing the opportunity to conduct this study. The authors would also like to thank all the patients and the technical staffs for their help during this research.

Funding

To conduct this study no fund was obtained from any sources. 


\section{Availability of data and materials}

The raw data can be made available to the interested researchers by the authors of this article if requested.

\section{Authors' contributions}

NDP and AOK, designed and carried out the research works, analyzed data, and prepared the manuscript. RB, SK, KLS and SKU contributed in research works and analysis of the data. AP, BL, BRR monitored the study. All authors read and approved the final manuscript.

\section{Competing interests}

The authors declare that they have no competing interests.

\section{Consent for publication}

Not applicable.

\section{Ethics approval and consent to participate}

Before start of the study, the research protocol was approved by KIST Medical College and Teaching Hospital, Lalitpur, Nepal and Goldengate International College, Kathmandu, Nepal. Informed consent was taken from all the patients or patient's guardians. The research was in compliance with the Helsinki Declaration.

\section{Author details}

${ }^{1}$ Department of Microbiology, Goldengate International College, Battisputali, Kathmandu, Nepal. ${ }^{2}$ Department of Microbiology, Grande International Hospital, Dhapasi, Kathmandu, Nepal. ${ }^{3}$ Department of Microbiology, KIST Medical College and Teaching Hospital, Lalitpur, Nepal.

Received: 20 June 2016 Accepted: 5 July 2016

Published online: 21 July 2016

\section{References}

1. Papa R, Artini M, Cellini A, Tilotta M, Galano E, Pucci P, et al. A new antiinfective strategy to reduce the spreading of antibiotic resistance by the action on adhesion-mediated virulence factors in Staphylococcus aureus. Microb Pathog. 2013;63:44-53.

2. Deurenberg RH, Vink C, Kalenic S, Friedrich AW, Bruggeman CA Stobberingh EE. The molecular evolution of methicillin-resistant Staphylococcus aureus. Clin Microbiol Infect. 2007;13(3):222-35.

3. Fournier B, Philpott DJ. Recognition of Staphylococcus aureus by the innate immune system. Clin Microbiol Rev. 2005;18(3):521-40.

4. David MZ, Daum RS. Community-associated methicillin-resistant Staphylococcus aureus: epidemiology and clinical consequences of an emerging epidemic. Clin Microbiol Rev. 2010;23(3):616-87.

5. Fall C, Richard V, Dufougeray A, Biron A, Seck A, Laurent F, et al. Staphylococcus aureus nasal and pharyngeal carriage in Senegal. Clin Microbiol Infect. 2014;20(4):0239-41.

6. Pirvanescu H, Balasoiu M, Ciurea ME, Balasoiu AT, Manescu R. Wound infections with multi-drug resistant bacteria. Chirurgia. 2014;109(1):73-9.

7. Chambers HF, Deleo FR. Waves of resistance: Staphylococcus aureus in the antibiotic era. Nat Rev Microbiol. 2009;7(9):629-41.

8. Moore MR, Perdreau-Remington F, Chambers HF. Vancomycin treatment failure associated with heterogeneous vancomycin-intermediate Staphylococcus aureus in a patient with endocarditis and in the rabbit model of endocarditis. Antimicrob Agents Chemother. 2003;47(4):1262-6.

9. Song JH, Hsueh PR, Chung DR, Ko KS, Kang Cl, Peck KR, et al. Spread of methicillin-resistant Staphylococcus aureus between the community and the hospitals in Asian countries: an ANSORP study. J Antimicrob Chemother. 2011;66(5):1061-9.

10. Finks J, Wells E, Dyke TL, Husain N, Plizga L, Heddurshetti R, et al. Vancomycin-resistant Staphylococcus aureus, Michigan, USA, 2007. Emerg Infect Dis. 2009;15(6):943-5.

11. Amatya R, Devkota P, Gautam A. Reduced susceptibility to vancomycin in methicillin resistant Staphylococcus aureus: a time for action. Nepal Med Coll J. 2014;16(1):42-4.

12. Chen SY, Liao CH, Wang JL, Chiang WC, Lai MS, Chie WC, et al. Method-specific performance of vancomycin MIC susceptibility tests in predicting mortality of patients with methicillin-resistant Staphylococcus aureus bacteraemia. J Antimicrob Chemother. 2014;69(1):211-8.
13. Pahadi PC, Shrestha UT, Adhikari N, Shah PK, Amatya R. Growing resistance to vancomycin among methicillin resistant Staphylococcus aureus isolates from different clinical samples. J Nepal Med Assoc. 2014;52(196):977-81.

14. Clinical Laboratory Standards Institute (CLSI). CLSI Document M100S-S22. Performance Standards for Antimicrobial Susceptibility Testing: Twenty Third Informational Supplement ed. Wayne: CLSI; 2012.

15. Andrews JM. Determination of minimum inhibitory concentrations. J Antimicrob Chemother. 2001;1:5-16.

16. Tisinger CK. Empowering your patients in the fight against methicillinresistant Staphylococcus aureus. J Am Acad Nurse Pract. 2008;20(4):204-11.

17. Terp S, Krishnadasan A, Bowen W, Joo J, Furoy D, Chan J, et al. Introduction of rapid methicillin-resistant Staphylococcus aureus polymerase chain reaction testing and antibiotic selection among hospitalized patients with purulent skin infections. Clin Infect Dis. 2014;58(8):22.

18. Sanjana RK, Shah R, Chaudhary N, Singh Yl. Prevalence and antimicrobial susceptibility pattern of methicillin-resistant Staphylococcus aureus (MRSA) in CMS-teaching hospital: a preliminary report. J Coll Med Sci Nepal. 2010;6:1-6.

19. Juayang AC, de Los Reyes GB, de la Rama AJ, Gallega CT. Antibiotic Resistance Profiling of Staphylococcus aureus Isolated from Clinical Specimens in a Tertiary Hospital from 2010 to 2012. Interdiscip Perspect Infect Dis. 2014;2014:898457.

20. Subedi S, Brahmadathan KN. Antimicrobial susceptibility patterns of clinical isolates of Staphylococcus aureus in Nepal. Clin Microbiol Infect. 2005;11(3):235-7.

21. Baral R, Khanal B, Acharya A. Antimicrobial susceptibility patterns of clinical isolates of Staphylococcus aureus in Eastern Nepal. Health Renaissance. 2011; 9:78-82.

22. Pandey S, Raza MS, Bhatta CP. Prevalence and antibiotic sensitivity pattern of Methicillin-Resistant-Staphylococcus aureus in Kathmandu Medical College-Teaching Hospital. J Inst Med. 2012;34:13-7.

23. Kumari N, Mohapatra TM, Singh YI. Prevalence of Methicillin-resistant Staphylococcus aureus (MRSA) in a Tertiary-Care Hospital in Eastern Nepal. JNMA J Nepal Med Assoc. 2008;47(170):53-6.

24. Arora S, Devi P, Arora U, Devi B. Prevalence of Methicillin-resistant Staphylococcus Aureus (MRSA) in a Tertiary Care Hospital in Northern India. J Lab Physicians. 2010;2(2):78-81.

25. Dibah S, Arzanlou M, Jannati E, Shapouri R. Prevalence and antimicrobial resistance pattern of methicillin resistant Staphylococcus aureus (MRSA) strains isolated from clinical specimens in Ardabil, Iran. Iran J Microbiol. 2014;6(3):163-8.

26. Khanal LK, Jha BK. Prevalence of methicillin resistant Staphylococcus aureus (MRSA) among skin infection cases at a hospital in Chitwan, Nepal. Nepal Med Coll J. 2010;12(4):224-8.

27. Tiwari HK, Das AK, Sapkota D, Sivrajan K, Pahwa VK. Methicillin resistant Staphylococcus aureus: prevalence and antibiogram in a tertiary care hospital in western Nepal. J Infect Dev Ctries. 2009;3(9):681-4.

28. Pant ND, Sharma M. Carriage of methicillin resistant Staphylococcus aureus and awareness of infection control among health care workers working in intensive care unit of a hospital in Nepal. Braz J Infect Dis. 2016;20(2):218-9.

29. Nathwani D. Impact of methicillin-resistant Staphylococcus aureus infections on key health economic outcomes: does reducing the length of hospital stay matter? J Antimicrob Chemother. 2003;51(S2):ii37-44.

30. Dumitrescu O, Lina G. What is the place of linezolid in the treatment of methicillin-resistant Staphylococcus aureus nosocomial pneumonia and complicated skin and soft tissue infections in Europe? Clin Microbiol Infect. 2014:4:1-2.

31. Dezfulian A, Aslani MM, Oskoui M, Farrokh P, Azimirad M, Dabiri H, et al. Identification and Characterization of a High Vancomycin-Resistant Staphylococcus aureus Harboring VanA Gene Cluster Isolated from Diabetic Foot Ulcer. Iran J Basic Med Sci. 2012;15(2):803-6.

32. Tiwari HK, Sen MR. Emergence of vancomycin resistant Staphylococcus aureus (VRSA) from a tertiary care hospital from northern part of India. BMC Infect Dis. 2006;6:156.

33. Thati V, Shivannavar CT, Gaddad SM. Vancomycin resistance among methicillin resistant Staphylococcus aureus isolates from intensive care units of tertiary care hospitals in Hyderabad. Indian J Med Res. 2011;134:704-8.

34. Sharma P, Vishwanath G. Study of vancomycin susceptibility in methicillinresistant Staphylococcus aureus isolated from clinical samples. Ann Trop Med Public Health. 2012;5:178-80.

35. Hasan R, Acharjee M, Noor R. Prevalence of vancomycin resistant Staphylococcus aureus (VRSA) in methicillin resistant S. aureus (MRSA) strains isolated from burn wound infections. Tzu Chi Med J. 2016;28(2):49-53. 
36. Osman MM, Osman MM, Mohamed NA, Osman SM, Magzoub M, El-Sanousi SM. Investigation on Vancomycin Resistance (VRSA) among Methicillin Resistant S. aureus (MRSA) in Khartoum State, Sudan. Am J Microbiol Res. 2016:4(2):56-60.

37. Pallazo ICV, Araujo MLC, Darini ALC. First Report of Vancomycin-Resistant Staphylococci Isolated from Healthy Carriers in Brazil. J Clin Microbiol. 2005; 43:179-85.

38. Neupane S, Pant ND, Khatiwada S, Chaudhary R, Banjara MR. Correlation between biofilm formation and resistance toward different commonly used antibiotics along with extended spectrum beta lactamase production in uropathogenic Escherichia coli isolated from the patients suspected of urinary tract infections visiting Shree Birendra Hospital, Chhauni, Kathmandu, Nepal. Antimicrob Resist Infect Control. 2016;5:5.

39. Awasthi TR, Pant ND, Dahal PR. Prevalence of Multidrug resistant bacteria in causing community acquired urinary tract infection among the patients attending outpatient Department of Seti Zonal Hospital, Dhangadi, Nepal. Nepal J Biotechnol. 2015:3(1):55-9.

40. Shrestha KL, Pant ND, Bhandari R, Khatri S, Shrestha B, Lekhak B. Reemergence of the susceptibility of the Salmonella spp. isolated from blood samples to conventional firstline antibiotics. Antimicrob Resist Infect Control. 2016;5:22

\section{Submit your next manuscript to BioMed Central} and we will help you at every step:

- We accept pre-submission inquiries

- Our selector tool helps you to find the most relevant journal

- We provide round the clock customer support

- Convenient online submission

- Thorough peer review

- Inclusion in PubMed and all major indexing services

- Maximum visibility for your research

Submit your manuscript at www.biomedcentral.com/submit 